\title{
Effects of a 2-Year Supervised Exercise Program Upon the Body Composition and Muscular Performance of HIV-Infected Patients
}

\author{
Lorena da Silva Paes ${ }^{1}$, Juliana Pereira Borges ${ }^{1}$, Fernanda Monteiro dos Santos ${ }^{1}$, Taciana Pinto de Oliveira ${ }^{1}$, \\ Jaciara Gomes Dupin ${ }^{1}$, Elizabeth Assumpção Harris ${ }^{1}$ and Paulo Farinatti ${ }^{*}, 1,2$ \\ ${ }^{I}$ Laboratory of Physical Activity and Health Promotion, Institute of Physical Education and Sports, Rio de Janeiro State \\ University, Rio de Janeiro, RJ, Brazil \\ ${ }^{2}$ Graduate Program in Physical Activity Sciences, Salgado de Oliveira University, Niteroi, RJ, Brazil
}

\begin{abstract}
Background: There is a lack of research investigating long-term effects of exercise training upon the body
composition and muscle function in HIV-infected patients (PHIV). The study investigated the influence of a 2-year
Abstract: Background: There is a lack of research investigating long-term effects of exercise training upon the body
composition and muscle function in HIV-infected patients (PHIV). The study investigated the influence of a 2-year supervised exercise program on body composition and strength of PHIV under highly active antiretroviral therapy (HAART).

Methods: A training program including aerobic, strength and flexibility exercises was performed by 27 PHIV (17 men/ 10 women; age: $48.7 \pm 7.0$ years; HAART: $150.7 \pm 65.3$ months) during 1 year and 18 PHIV (10 men/ 8 women; age: $50.6 \pm 5.2$ years; HAART: 176.6 \pm 53.1 months) during 2 years. Body composition and knee isokinetic strength were assessed at baseline and at the end of each year of intervention.

Results: Body composition remained stable along the whole experiment $v$ s baseline (1-year - total muscle mass: $\Delta$ men $=1.1 \%, P=0.21 ; \Delta$ women=1.4\%, $P=0.06$; trunk fat: $\Delta$ men=-0.1\%, $P=0.65 ; \Delta$ women $=-1.5 \%, P=0.45 ; 2$ years - total muscle mass: $\Delta$ men=2.7\%, $P=0.54 ; \Delta$ women=-1.9\%, $P=0.71 ;$ trunk fat: $\Delta$ men $=4.4 \%, P=0.96 ; \Delta$ women=10.0\%, $P=0.30)$. After 1 -year, peak torque increased in men ( $\Delta$ extension $=4.2 \%, P=0.01 ; \Delta$ flexion $=12.2 \%, P=0.04)$ and total work reduced in women $(\Delta$ extension $=-15.4 \%, P=0.01, \Delta$ flexion=-17.5\%,P=0.05). All strength markers remained stable $v s$ baseline after 2 years of intervention $(P>0.05)$. Only men showed significant reduction in the risk of disability due to sarcopenia $(P=0.05)$ after 1 year of intervention, which remained stable after 2 years.

Conclusion: Long-term exercise training preserved strength and muscle mass in PHIV under HAART. Exercise programs should be part of HIV therapy to prevent sarcopenia of this population along the years.
\end{abstract}

Trial Registration: ACTRN12610000683033; UTN U1111-1116-4416.

Keywords: AIDS, fitness, HAART, health, muscle mass, physical activity, strength.

\section{INTRODUCTION}

\footnotetext{
*Address correspondence to this author at the Laboratory of Physical
Activity and Health Promotion (LABSAU), Rua São Francisco Xavier, 524,

*Address correspondence to this author at the Laboratory of Physical
Activity and Health Promotion (LABSAU), Rua São Francisco Xavier, 524, sala 8133 F, Maracanã, Rio de Janeiro, RJ, CEP 20550-013, Brazil;

Tel: (+55-21) 2334-0775; Fax: (+55-21) 2334-0002; E-mail: paulo.farinatti@pq.cnpq.br
}

\section{HIV-infected patients (PHIV) under highly active antiretroviral therapy (HAART) might exhibit collateral effects as increased proinflammatory profile [1,2], hormonal impairment [2] and metabolic dysfunction [1-3]. Additionally to poor immunity [4] PHIV frequently exhibit greater accumulation of central adiposity and lipodystrophy $[1,5]$, chronic low-grade inflammation, and compromised growth hormone pulsatility (GH) [2, 6], among other consequences of the combination between HIV and HAART. Altogether these effects may contribute to the manifestation of an early "somatopause" in middle-aged PHIV [7], therefore increasing the risk of sarcopenia and premature physical disability [8].}


would be capable to improve the muscle function in PHIV, and the extent to which this response would be related to sustained increase in muscle mass is yet to be defined.

Therefore, the purpose of this pre-post trial was to investigate the effects of a 2-year supervised exercise program upon the muscle strength and body composition of PHIV under HAART. We also assessed the prevalence of sarcopenia in these patients, based on cut-off points previously proposed $[26,27]$. It has been hypothesized that the exercise program would induce gains in strength performance and muscle mass of PHIV, therefore reducing the prevalence and risk for disability due to sarcopenia.

\section{METHODS}

\section{Subjects}

Sixty-seven previously sedentary PHIV (48 men and 19 women) attending the infectious diseases outpatient clinic of the Pedro Ernesto Hospital of the University of Rio de Janeiro State, Brazil (HUPE-UERJ) initially volunteered for the study $(57.5 \pm 6.0$ years; $64.0 \pm 12.1 \mathrm{~kg} ; 1.66 \pm 0.1 \mathrm{~m})$. Eligible subjects should be older than 18 years-old and be under HAART treatment for at least 12 months. Exclusion criteria were: a) AIDS diagnosis; b) cerebral toxoplasmosis or any infectious diseases compromising the central nervous system; d) use of anabolic hormone therapy or ergogenic resources to gain muscle mass; e) cardiovascular, respiratory, bone, muscle, or joint problems that could limit physical function; f) less than $75 \%$ of attendance to the exercise sessions.

The PHIV were assigned into gender groups: HIV- men (HIV-M) and HIV-women (HIV-W). We considered as control reference the baseline data assessed before the exercise intervention. Due to ethical reasons, patients with less than $75 \%$ of attendance to the planned exercise sessions continued to exercise and therefore could not be regarded as drop-outs. In other words, only their data were not considered in the study due to low attendance.

Fig. (1) illustrates sample selection and drop-outs throughout the study. From the 67 initial volunteers, 10 were considered as not eligible according to exclusion criteria, since they exhibited cardiovascular disease (1 man), intermittent claudication (1 man), neurologic problems due to recent toxoplasmosis $(3 \mathrm{men})$, or poor compliance to HAART ( 3 men and 2 women). After two years, 28 PHIV (23 men and 7 women) dropped out due to specific clinical and personal issues as work activities, disease, surgeries, motivation (i.e. family, travelling, reduced mood), or difficult access to the exercise facilities (i.e. traffic or long distance). Data from another 11 subjects $(7 \mathrm{men}$ and 2 women) were excluded from the analysis due to insufficient attendance $(<75 \%$ of exercise sessions), but these patients continued to exercise. In brief, 27 patients were assessed after 1-year experiment (17 men and 10 women; $48.7 \pm 7.0$ years) and from these, 18 patients completed two years of intervention (10 men and 8 women; 50.6 \pm 5.2 years).
The study protocol was approved by institutional ethics committee and all volunteers gave informed written consent before participation in the study, according to the recommendations of the Helsinki Convention.

\section{Experimental Design}

The supervised exercise program took place between 2011 and 2013 and included aerobic, strength and flexibility exercises at the University of Rio de Janeiro State (UERJ) facilities. Participants were individually supervised by their physician assistants, in order to control their immunological status and drug therapy. The supervised exercise program took place three times per week, either in the morning or afternoon, according to patients' best convenience. Training sessions occurred in all months of the year, except for a vacation interval from mid December to mid January. During this period the patients were recommended to keep physically active, by performing light tasks as walking or cycling. As part of the exercise program evaluations, all PHIV had their body composition and strength routinely assessed every year. Data were obtained in two visits to the laboratory, always in the morning period (8:00 to 11:00 a.m.). In the first visit the body composition was assessed by means of dual energy X-ray absorptiometry (DXA). After 24 to $72 \mathrm{~h}$ patients performed the isokinetic strength tests.

\section{Body Composition Assessment}

The DXA was used to assess whole and regional body composition (Hologic QDR 4500, Hologic ${ }^{\mathrm{TM}}$, Bedford, MA, USA). The DXA allows assessing body composition changes due to long-term infection and HAART, as the uneven distribution of fat, osteopenia and reduced skeletal muscle mass. The equipment was calibrated according to manufacturer instructions. Subjects were scanned in the supine position using standard protocols. Scans were performed in high resolution and analyzed by the same trained technician. Principles underlying DXA analyses were described elsewhere [28].

\section{Isokinetic Strength Assessment}

The strength of lower limbs was measured using a Biodex System 4 PRO isokinetic dynamometer Biodex $^{\text {TM }}$ Medical Systems Inc., Shirley, NY). Calibration of the equipment was performed according to the manufacturer's specifications before every testing session. Prior to the tests the participants performed a specific warm-up in the isokinetic dynamometer (15 repetitions with angular velocity fixed at $\left.120^{\circ} \cdot \mathrm{s}^{-1}\right)$.

The maximal isokinetic force protocol involved knee extensors and flexors in concentric-eccentric muscle action with the dominant limb. The range of motion varied between $0^{\circ}$ to $90^{\circ}$ with execution speed fixed in $60^{\circ} \cdot \mathrm{s}^{-1}$. Subjects were verbally encouraged to perform maximal effort during 3 sets of 10 repetitions with $120 \mathrm{~s}$ intervals between sets. Peak torque, power output and total work were measured as 
67 PHIV volunteered between 2011-2013

$(M=48 ; W=19)$

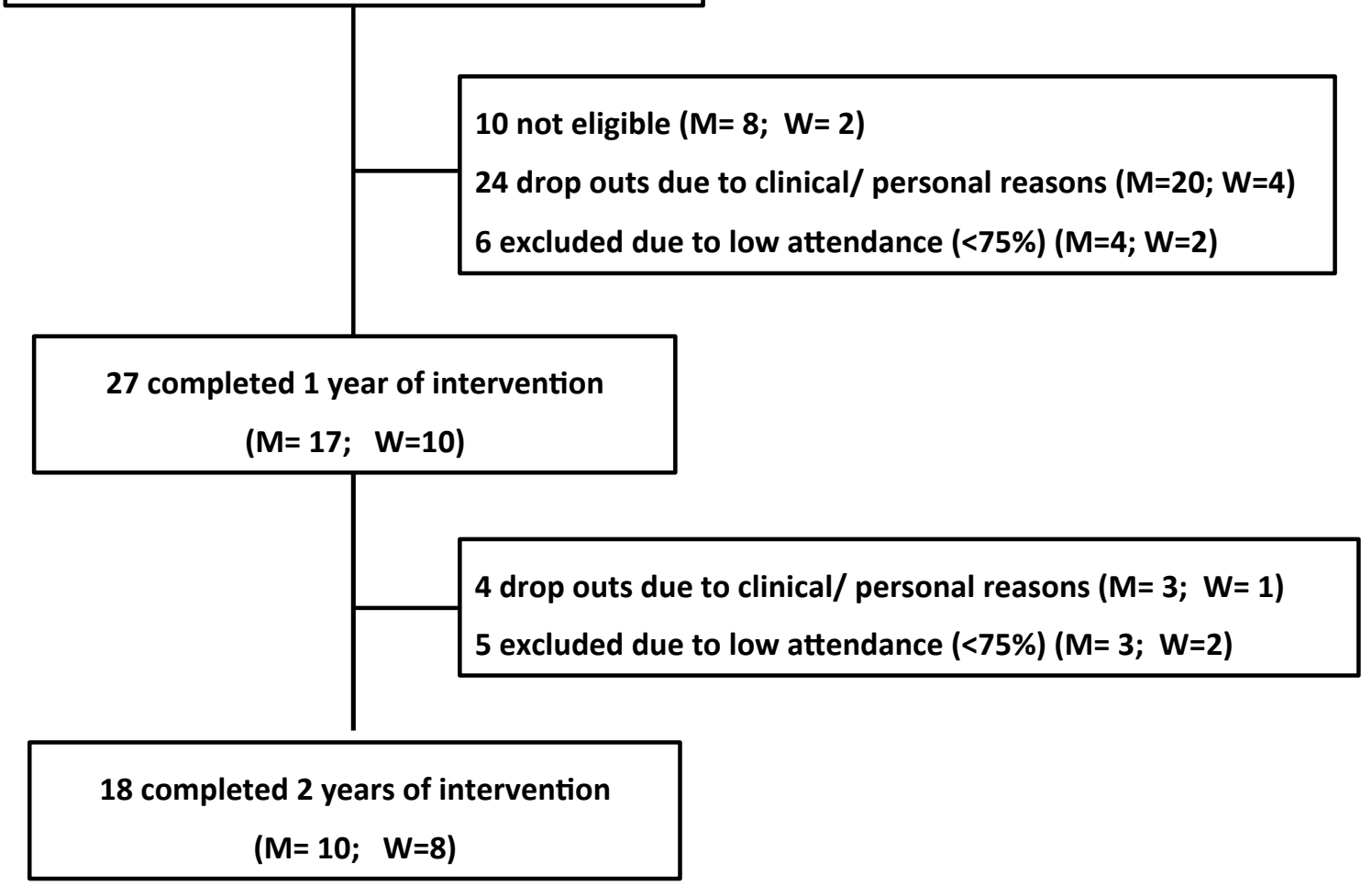

Fig. (1). Flowchart of sample selection.

indicators of force production and muscular resistance capacity. Percent delta $(\Delta \%)$ was used to calculate variations in each variable over the years. All tests were considered as valid only when the coefficient of variation between sets was lower than $15 \%$ as described elsewhere [29].

\section{Sarcopenia Cut Off Points}

The lean mass $(\mathrm{Kg})$ of legs and arms was used to calculate the appendicular skeletal muscle mass (ASM). Cutoff values for sarcopenia proposed by Baumgartner et al. [26] in each sex were defined as values two standard deviations below sex-specific means from reference data for young adults aged 18-40 years obtained in the Rosetta Study [30]. Cut-off points considering the ratio between ASM and height squared were of $7.26 \mathrm{~kg} / \mathrm{m}^{2}$ for men and $5.45 \mathrm{~kg} / \mathrm{m}^{2}$ for women were adopted to classify individuals as sarcopenic. Janssen et al. [27] normalized the total skeletal muscle mass (SMM) for height (muscle mass $(\mathrm{kg}) /$ height $\left.(\mathrm{m})^{2}\right)$ and termed it as SMM index. Cut-off points of 5.766.75 and $\leq 5.75 \mathrm{~kg} / \mathrm{m}^{2}$ were reported to denote SMM index related to moderate to high risk of disability from sarcopenia in women. The corresponding values for men were 8.5110.75 and $\leq 8.50 \mathrm{~kg} / \mathrm{m}^{2}$.

These indices were created considering that the functional capacity related to a given amount muscle mass depends on individual body dimensions. Therefore, in Baumgartner and Janssen indices the muscle mass (appendicular and total, respectively) are related to height squared. The specific meaning of these indices also differ - while Baumgartner et al. [26] proposed cut off points to identify sarcopenia, the major concern of Janssen et al. [27] was to classify the risk for disability due to such important loss of muscle mass.

\section{Exercise Intervention}

Typically, participants trained three times per week in 60 to $90 \mathrm{~min}$ sessions including aerobic, resistance and flexibility exercises, as described elsewhere [11]. Aerobic training was performed on cyclo-ergometer or treadmill for $30-40 \mathrm{~min}$ at moderate intensity [50-80\% reserve heart rate] to avoid possible exercise-induced immunodepression [31]. Resistance training included 8 to 10 single and multi-joint exercises (free weights and machines) for the upper and lower body, performed with 2 to 3 sets of 12 to 15 repetitions and load corresponding to $80-90 \%$ of 12 repetition maximum. The workload was adjusted every two months as described elsewhere [11, 32]. At the end of the sessions participants performed stretching exercises for the major joints using the static method [2 sets of 6 to 8 exercises with 30-s duration]. All training sessions were supervised by exercise specialists on a one-to-one basis or in small groups (4-5 subjects per instructor).

\section{Statistical Analysis}

Normal distribution of data was confirmed by the Kolmogorov-Smirnov test and therefore results are presented as means \pm standard deviations. Comparisons between groups were performed by repeated measures ANOVA 
followed by Bonferroni post-hoc verifications in the event of significant $F$ ratios. Chi-square $\left(\chi^{2}\right)$ was used to compare the pre $v s$ post-intervention frequency of sarcopenia in the total sample and gender groups. All calculations were performed using the Statistica 7.0 software $\left(\right.$ Statsoft $^{\mathrm{TM}}$, Tulsa, OK, USA) and the probability level for statistical significance was set at $P \leq 0.05$.

\section{RESULTS}

\section{Program Adherence}

An achieved statistical power of 0.793 for an effect size of 2.5 was obtained by performing a post hoc analysis (GPower version 3.0.10; Kiel, University of Kiel, Germany) based on the given sample size and predefined $P$ value. No case of AIDS diagnostics or death was reported during the study, nor injuries or problems due to the exercise intervention. As aforementioned, 27 PHIV completed 1 year of intervention (17 men and 10 women) and 18 completed 2 years of this intervention ( 10 men and 8 women). The average adherence of those who remained in the study was $81 \%$ and $79 \%$ for 1 year and 2 years training groups, respectively. All PHIV were under HAART for at least 80 months (150.7 \pm 65.3 months).

\section{Clinical Conditions and Body Composition}

Baseline subjects' characteristics and relative variation throughout 2 years of intervention with regard to clinical conditions and body composition are presented in Tables $\mathbf{1}$ and 2 for men and women, respectively. At baseline the viral load was undetectable $(<50$ copies $/ \mathrm{mL})$ for most patients. Only two men presented values above this cut-off point in 2011 and 2012 (2095 and 81 copies; 2518 and 3451 copies) and one man in 2013 (388 copies). All women showed undetectable viral load throughout the whole training period. $\mathrm{T}$ CD4+ count did not alter with the intervention 1 year later (men: $\Delta \%=17.7, \mathrm{P}=0.51, \Delta \%=18.8$ and $\Delta \%=-12.7 \%$ and women $=0.82$ ) and 2 years later (men: $\Delta \%=12.7, \mathrm{P}=0.71$ and women: $\Delta \%=4.2, \mathrm{P}=0.98)$.

In regards to the muscle mass after 1 year of training program, slight albeit non significant increases have been observed in SMM (men: $1.1 \%, \mathrm{P}=0.21$ and women: $1.4 \%$, $\mathrm{P}=0.06$ ) and ASM (men: $1.5 \%, \mathrm{P}=0.20$ and women: $0.4 \%$, $\mathrm{P}=0.71)$. The trunk fat remained quite stable in both men ($0.1 \%, \mathrm{P}=0.65)$ and women $(-1.5 \%, \mathrm{P}=0.45)$. In the 2 -years intervention group, SMM, ASM and body fat were maintained without expressive variations in both gender groups (Tables 1 and 2). Total muscle mass index (SMM index) applied to calculate sarcopenia cut-off points also remained stable over 1 -year (men $\mathrm{P}=0.07$; women: $\mathrm{P}=0.71$ ) and 2-years of intervention (men $\mathrm{P}=0.14$; women: $\mathrm{P}=0.86$ ).

\section{Strength Performance}

Table 3 depicts markers of strength performance obtained in the isokinetic strength assessment. After 1 year of intervention, men presented significant increase in the maximal strength (peak torque) in relation to baseline, in both EXT and FLX $(\Delta \%=4.2 \%, \quad \mathrm{P}=0.01 ; \Delta \%=12.2 \%$,

Table 1. Baseline and relative changes $(\Delta \%)$ in clinical conditions and body composition in men.

\begin{tabular}{|c|c|c|c|c|c|c|c|c|}
\hline Age (years old) & $47.0(7.5)$ & - & - & $48.8(5.7)$ & - & - & - & - \\
\hline Time of HIV infection (months) & $187.2(75.1)$ & - & - & $217.5(72.1)$ & - & - & - & - \\
\hline \multicolumn{9}{|l|}{ Body Composition } \\
\hline Body weight $(\mathrm{kg})$ & $69.2(10.4)$ & $3.0 \%$ & 0.17 & $66.1(6.9)$ & $7.5 \%$ & $2.1 \%$ & $9.7 \%$ & 0.57 \\
\hline BMI $\left(\mathrm{kg} / \mathrm{m}^{2}\right)$ & $22.8(2.8)$ & $2.6 \%$ & 0.24 & $22.6(2.0)$ & $2.2 \%$ & $2.5 \%$ & $4.0 \%$ & 0.92 \\
\hline SMM (kg) & $51.8(3.8)$ & $1.1 \%$ & 0.21 & $51.7(2.0)$ & $2.0 \%$ & $0.7 \%$ & $2.7 \%$ & 0.54 \\
\hline Trunk fat (\%) & $27.7(11.1)$ & $-0.1 \%$ & 0.65 & $28.8(12.1)$ & $2.4 \%$ & $3.8 \%$ & $4.4 \%$ & 0.96 \\
\hline Fat mass $(\mathrm{kg})$ & $15.4(6.9)$ & $4.5 \%$ & 0.55 & $16.9(4.9)$ & $-6.3 \%$ & $7.9 \%$ & $0.6 \%$ & 0.78 \\
\hline BMD (\%) & $1.06(0.1)$ & $0.1 \%$ & 0.90 & $1.03(0.0)$ & $0.5 \%$ & $1.1 \%$ & $1.6 \%$ & 0.85 \\
\hline \multicolumn{9}{|l|}{ Muscle Mass Indexes } \\
\hline ASM index $\left(\mathrm{kg} / \mathrm{m}^{2}\right)$ & $7.8(0.7)$ & $3.1 \%$ & 0.21 & $7.9(0.2)$ & $3.3 \%$ & $1.3 \%$ & $4.5 \%$ & 0.35 \\
\hline SMM index $\left(\mathrm{kg} / \mathrm{m}^{2}\right)$ & $8.4(0.8)$ & $5.6 \%$ & 0.07 & $8.5(0.3)$ & $3.4 \%$ & $-2.4 \%$ & $0.8 \%$ & 0.54 \\
\hline
\end{tabular}

Baseline values shown as mean (standard deviation) and variations as average percent delta ( $\Delta \%)$. BMI: body mass index, ASM: appendicular skeletal muscle mass, SMM: total skeletal muscle mass, BMD: bone mineral density, ASM index: Appendicular skeletal muscle mass index adopted for sarcopenia cut-off points (Baumgartner et al. [26]), SMM index: Total skeletal muscle mass index adopted for sarcopenia cut-off points (Janssen et al. [27]). 
Table 2. Baseline and relative changes $(\Delta \%)$ in clinical conditions and body composition in women.

\begin{tabular}{|c|c|c|c|c|c|c|c|c|}
\hline \multirow{2}{*}{ Variables } & \multicolumn{3}{|c|}{1 Year $(n=10)$} & \multicolumn{5}{|c|}{2 Years $(n=7)$} \\
\hline & Baseline & $\begin{array}{c}\Delta \% \text { Baseline } v s \\
1 \text { Year }\end{array}$ & P-Value & Baseline & $\begin{array}{c}\Delta \% \text { Baseline } v s \\
1 \text { Year }\end{array}$ & $\begin{array}{l}\Delta \% 1 v s \\
2 \text { Years }\end{array}$ & $\begin{array}{c}\Delta \% \text { Baseline } v s \\
2 \text { Years }\end{array}$ & P-Value \\
\hline Age (years old) & $50.3(5.3)$ & - & - & $52.0(4.4)$ & - & - & - & - \\
\hline Time of HIV infection (months) & $157.3(68.2)$ & - & - & $188.0(55.6)$ & - & - & - & - \\
\hline Time of HAART (months) & $121.3(43.4)$ & - & - & $148.0(24.7)$ & - & - & - & - \\
\hline T CD4+ $\left(\right.$ cell $\left./ \mathrm{mm}^{3}\right)$ & $724.8(393.2)$ & $1.9 \%$ & 0.82 & $786.2(307.2)$ & $10.8 \%$ & $-6.9 \%$ & $4.2 \%$ & 0.98 \\
\hline \multicolumn{9}{|l|}{ Body Composition } \\
\hline Body weight (kg) & $56.2(10.4)$ & $1.3 \%$ & 0.09 & $59.4(10.7)$ & $-0.2 \%$ & $1.6 \%$ & $1.4 \%$ & 0.48 \\
\hline BMI $\left(\mathrm{kg} / \mathrm{m}^{2}\right)$ & $23.1(3.8)$ & $-1.5 \%$ & 0.54 & $24.1(3.7)$ & -2.9 & $1.6 \%$ & $-1.2 \%$ & 0.60 \\
\hline SMM (kg) & $36.9(3.8)$ & $1.4 \%$ & 0.06 & $38.7(4.3)$ & $-1.4 \%$ & $-0.4 \%$ & $-1.9 \%$ & 0.71 \\
\hline $\operatorname{ASM}(\mathrm{kg})$ & $16.3(2.0)$ & $0.4 \%$ & 0.71 & $17.0(2.2)$ & $-1.4 \%$ & $0.5 \%$ & $-0.9 \%$ & 0.68 \\
\hline Body fat $(\%)$ & $30.5(7.5)$ & $-1.0 \%$ & 0.59 & $30.9(7.5)$ & $3.0 \%$ & $6.7 \%$ & $9.6 \%$ & 0.29 \\
\hline Trunk fat (\%) & $33.3(8.7)$ & $-1.5 \%$ & 0.45 & $34.3(7.5)$ & $2.9 \%$ & $7.4 \%$ & $10.0 \%$ & 0.30 \\
\hline Fat mass (kg) & $16.8(8.3)$ & $0.6 \%$ & 0.80 & $18.2(8.3)$ & $3.0 \%$ & $9.1 \%$ & $11.9 \%$ & 0.24 \\
\hline BMD (\%) & $1.01(0.1)$ & $-0.0 \%$ & 0.69 & $1.01(0.1)$ & $-2.1 \%$ & $0.0 \%$ & $-2.0 \%$ & 0.17 \\
\hline \multicolumn{9}{|l|}{ Muscle Mass Indexes } \\
\hline ASM index $\left(\mathrm{kg} / \mathrm{m}^{2}\right)$ & $6.5(0.7)$ & $0.4 \%$ & 0.78 & $6.6(0.8)$ & $-0.8 \%$ & $0.5 \%$ & $-0.3 \%$ & 0.98 \\
\hline SMM index $\left(\mathrm{kg} / \mathrm{m}^{2}\right)$ & $6.9(0.8)$ & $0.5 \%$ & 0.71 & $7.1(0.9)$ & $-0.8 \%$ & $0.3 \%$ & $-0.4 \%$ & 0.99 \\
\hline
\end{tabular}

Baseline values shown as mean (standard deviation) and variations as average percent delta ( $\Delta \%)$. BMI: body mass index, ASM: appendicular skeletal muscle mass, SMM: total skeletal muscle mass, BMD: bone mineral density, ASM index: Appendicular skeletal muscle mass index adopted for sarcopenia cut-off points (Baumgartner et al. [26]), SMM index: Total skeletal muscle mass index adopted for sarcopenia cut-off points (Janssen et al. [27]).

$\mathrm{P}=0.04)$. Although average power and total work have increased in this group, they did not present significant difference in relation to baseline (average power - EXT: $\mathrm{P}=0.34$, FLX: $\mathrm{P}=0.14$; total work - EXT: $\mathrm{P}=0.14$, FLX: $\mathrm{P}=0.11)$. Strength markers in women also showed to be stable along 1 year of training (peak torque- $\mathrm{EXT}$ : $\mathrm{P}=0.52$, FLX: $\mathrm{P}=0.31$; average power - EXT: $\mathrm{P}=0.10$, FLX: $\mathrm{P}=0.09$ ). Total work, however, significantly decreased in women that completed 1 year of intervention (EXT: $\Delta \%=-15.4 \%$, $\mathrm{P}=0.01, \mathrm{FLX}: \Delta \%=-17.5 \%, \mathrm{P}=0.05)$. Overall, after 2 years of intervention both men and women tended to maintain their muscle strength, despite of slight oscillations over the years (gains and losses) in most assessed variables.

\section{Prevalence of Sarcopenia}

Table 4 depicts the frequency of sarcopenia before and after exercise interventions. Albeit the non significant values obtained for the chi-square, there was a slight trend of reduction or stabilization of the number of individuals classified as sarcopenic as defined by the ASM index. Men showed a significant reduction in disability due to sarcopenia based on SMM index cut-off values after 1 year of exercise intervention $\left(\chi^{2}=2.7, \mathrm{P}=0.05\right)$.

\section{DISCUSSION}

The present study aimed to investigate whether body composition and muscle function could be improved in PHIV after long term exercise training. The main finding was that an overall exercise training routine performed over 2 years was efficient to maintain muscle mass and muscle performance in $\mathrm{HIV}$-infected patients, therefore preventing sarcopenia and related risk of physical disability. Additionally, the immunological function reflected by CD4 count remained stable during the intervention.

A total of 29 randomized controlled trials could be found about exercise training for HIV-infected patients [21, 24, 3357]. From these, eight trials applied resistance training [21, 33-39], eight applied aerobic exercise [50-57], and 11 applied a combination of aerobic and resistance exercises (concurrent training) [42-49, 58], while two compared the effects of resistance $v s$ aerobic exercise [24, 40]. Sixteen studies measured both strength and body composition of participants [21, 24, 33-46], but only nine directly assessed the muscle mass [24, 33-39, 41]. As aforesaid, the majority of prior studies evaluating the effects of regular exercise in PHIV applied training protocols with relatively short duration. The duration of intervention programs specifically investigating the effects of exercise upon strength and body composition ranged from 6 to 16 weeks, but in approximately $20 \%$ of them it was shorter than nine weeks $[21,34,38]$.

A number of short-term studies succeeded to demonstrate gains in both strength and/or muscle mass in response to exercise protocols with quite different characteristics $[11,12$, 24,33 ], including a previous controlled trial from our group that applied during 12 weeks exactly the same training protocol as used herein [11]. In the present study the muscle strength remained stable compared to baseline in the 2-year 
Table 3. Baseline values and relative change $(\Delta \%)$ of muscle performance markers $(1$ year, $n=25 ; 2$ years, $n=13)$.

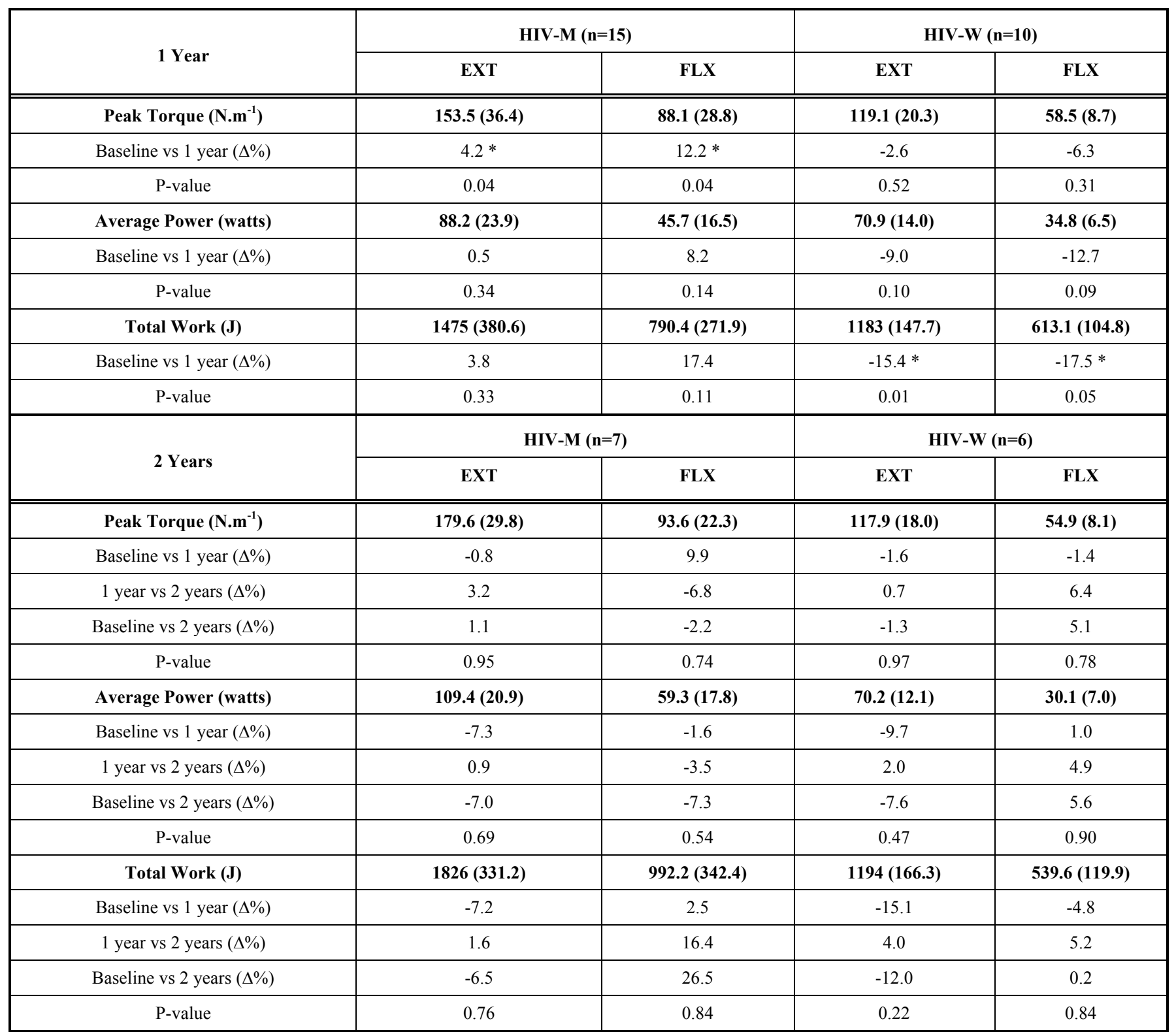

Baseline data are shown as absolute values ( \pm standard deviation) in bold and relative changes are summarized as average percent delta. ${ }^{*}$ : Significant difference compared to baseline $(P \leq 0.05)$. HIV-M: men and HIV-W: women. EXT: Knee Extension; FLX: knee Flexion.

group, but increased significantly in the group that trained during 1 year. However, these gains were not concomitant to an increase in muscle mass, which might suggest that even in long term exercise intervention strength improvements would be mostly related to neural adaptations than to muscle hypertrophy [19]. This finding is consistent with premises from prior research suggesting that PHIV could improve muscle fitness in the same manner as sarcopenic elder individuals [17]. Additionally, it is feasible to suppose from our findings that even if the hypertrophy capacity is impaired in PHIV, this does not necessarily imply inability of the muscle to respond to exercise stimuli, at least in the sense of increasing the functional capacity and preserving the existing tissue.

Evidently, the existence of a non exercise control group would help confirming such hypothesis, particularly if non exercise controls had reduced their muscle mass and strength along the years in comparison with the trained groups. In any case, investigations in this regard are scarce. Actually, we could find only one study demonstrating a consistent decline of muscle mass in sedentary PHIV over five years compared to healthy controls [41], which reinforces our presupposition. Unfortunately, it was not possible to set a control group in the present trial and further investigation is necessary to provide a better insight on this matter.

Overall, data for isokinetic strength assessment indicated that muscle performance was maintained along the 2 years of supervised training in both sexes. However, women exhibited a slight decrease in total work $(\sim 15 \%)$ in the first evaluation (1 year), which was kept stable after 2 years of intervention. The peak torque can be defined as the highest muscular force output at any moment during a repetition, and represents muscle's maximum strength capability. On the other hand, the total work reflects the muscle's capability to 
Table 4. Patients classified with moderate or high risk to physical disability due to sarcopenia according to the SMM index (Janssen et al. [27]) and as sarcopenic or non-sarcopenic according to the ASM index (Baumgartner et al. [26]) after 1 year and 2 years of supervised exercise intervention.

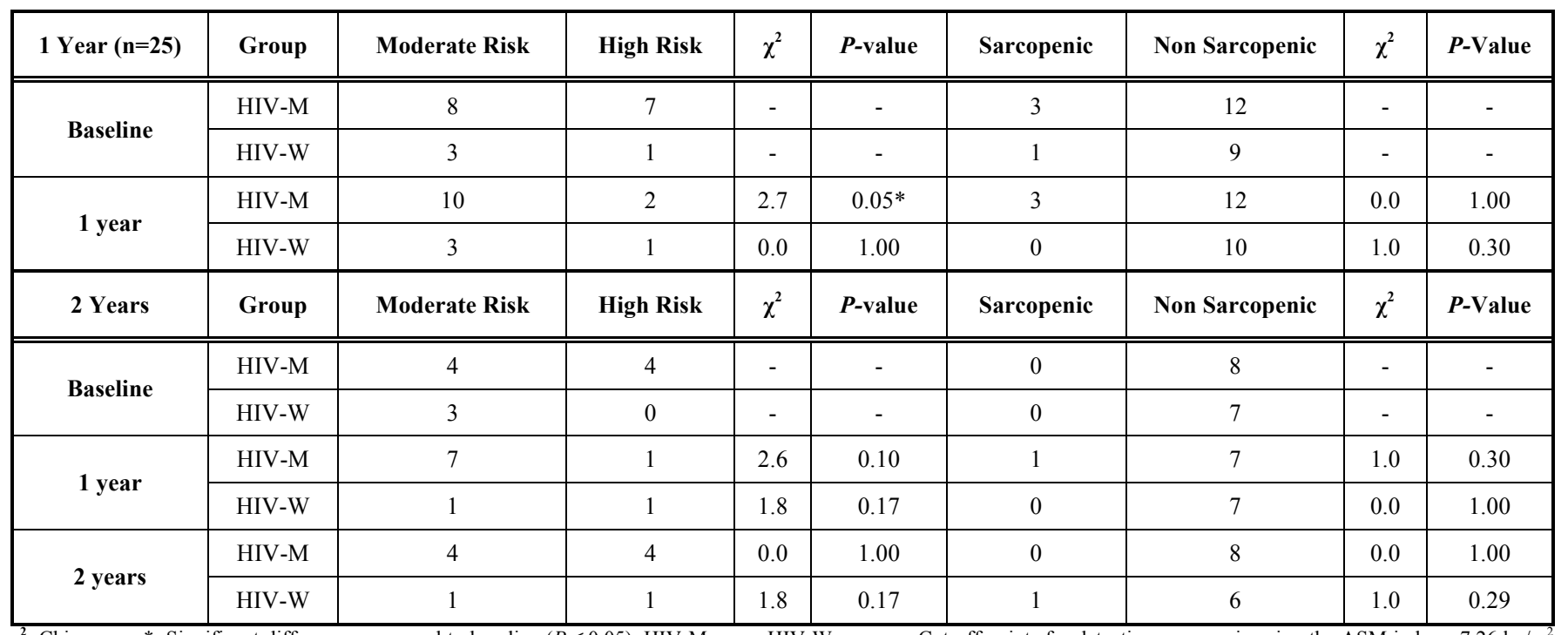

$\chi^{2}$ : Chi-square. *: Significant difference compared to baseline $(P \leq 0.05)$. HIV-M: men, HIV-W: women. Cut-off points for detecting sarcopenia using the ASM index - $7.26 \mathrm{~kg} / \mathrm{m}^{2}$ for men and $5.45 \mathrm{~kg} / \mathrm{m}^{2}$ for women Cut-off points related to moderate and high risk of disability from sarcopenia using the $\mathrm{SMM}$ index $-\mathrm{for}$ men: $8.51-10.75 \mathrm{~kg} / \mathrm{m}^{2}$ and $\leq 8.50 \mathrm{~kg} / \mathrm{m}^{2}$, respectively; for women: $5.76-6.75 \mathrm{~kg} / \mathrm{m}^{2}$ and $\leq 5.75 \mathrm{~kg} / \mathrm{m}^{2}$, respectively.

maintain torque throughout the whole test. In a few words, the total work might be affected by both maximal strength and accumulated stress due to successive sets [29, 59]. Since the peak torque/ power output in men and women remained stable along the supervised training, it is feasible to speculate that the decrease in total work observed in females could be related to higher muscle fatigue during the test. Prior studies reinforce this premise, suggesting that there would be gender related effects of HAART upon hormonal levels, muscle fibers, and mitochondrial dysfunction [2, 60]. Evidently, further research is warranted to ratify this possibility, since additional reduction in total work in women was not detected after 2 years, despite the fact that HAART was not discontinued.

The preservation of strength and muscle mass in our sample had implications on pre vs post prevalence of sarcopenia and related risk for disability, as evaluated by indexes usually applied in elderly populations [26, 61]. A significant and fast decline in muscle mass has been reported in PHIV under HAART $[41,62]$ with consequent repercussion on the ability to perform tasks demanding important strength levels [7, 8]. An increased prevalence of sarcopenia along the years would be therefore expected among sedentary PHIV [8]. Our data suggested that regular exercise of moderate intensity and volume is, at least, capable to preserve the muscle mass in HAART treated PHIV over relatively long periods of time - the prevalence of sarcopenia in men and women remained stable during the 2year follow up and decreased in men after 1-year intervention. To our knowledge, this is the first study to demonstrate that strength levels in PHIV may be increased or maintained due to exercise intervention longer than 1 year. Furthermore, it has been shown that this important functional outcome would be related to the preservation of muscle mass. Evidently, these findings should be taken into account in the context of long term treatment of PHIV - the beneficial effects of physical exercise seem to be consistent over the years, instead of transitory and limited to short periods.

The lack of a formal non exercise control is the major limitation of the present study. Actually, eligible patients that declined to participate of exercise training also refused to perform body composition and isokinetic assessments. For ethical reasons, those that fulfilled eligibility criteria could not be precluded to participate of the intervention. On the other hand, it is important to mention that previous research have adopted similar strategy of using preexercise data as a "control set" to investigate the effects of exercise upon muscle strength and mass in within-group trials [63]. Furthermore, follow ups investigating the effects of regular exercise for 1 year or more are very scarce - actually, most studies with concurrent training in HIV-patients are limited to 6-16 weeks, which limits inferences about the real impact of training on muscle mass and strength due to the major influence of gains related to neural adaptations [64-66]. On the other hand, the wasting syndrome is still a reality among HIV-infected patients, particularly when their come from low income social classes, which is the case of the majority of our patients. In this context, the present findings can be considered as clinically relevant despite the limitations of our protocol, since it has been originally demonstrated that long term exercise intervention is likely to preserve along the years the muscle mass, strength, and functionality of PHIV under HAART.

Additionally, it was not possible to control for changes in the antiretroviral type or dosage used by patients during the experiment. The HAART may include different drugs (i.e.: nucleoside transcriptase reverse inhibitors, protease inhibitors etc.) and depending on the type, dosage and time of utilization of a specific combination of them, different effects on mitochondrial function, muscle fiber and protein synthesis might be expected [3]. Also, analysis of other immunological markers (CD4:CD8 ratio, leukocytes count) 
would be useful to complement the immune markers presently assessed.

In conclusion, this pre-post intervention trial suggested that a supervised training program including aerobic, resistant, and flexibility exercises performed for 1 to 2 years would be capable to increase or maintain muscle performance and preserve muscle mass in HAART treated HIV-infected patients, with no apparently negative effects on the immunological function as reflected by the CD4 count. Long term physical exercise programs should be therefore considered as an essential part of HIV therapy, in order to prevent sarcopenia and preserve the functional autonomy of PHIV along the years. However, further research, particularly randomized controlled trials are warranted to ratify these preliminary results.

\section{CONFLICT OF INTEREST}

The authors confirm that this article content has no conflict of interest.

\section{ACKNOWLEDGEMENTS}

This work was partially supported by FAPERJ and CNPQ. We also thank the staff from the Interdisciplinary Nutritional Assessment Laboratory of the University of Rio de Janeiro State (LIAN) for conducting DXA exams.

\section{REFERENCES}

[1] Carr A, Cooper DA. Adverse effects of antiretroviral therapy. Lancet 2000; 356(9239): 1423-30.

[2] Cotter AG, Powderly WG. Endocrine complications of human immunodeficiency virus infection: hypogonadism, bone disease and tenofovir-related toxicity. Best Pract Res Clin Endocrinol Metab 2011; 25(3): 501-15

[3] Authier FJ, Gherardi RK. Muscular complications of human immunodeficiency virus (HIV) infection in the era of effective antiretroviral therapy. Rev Neurol (Paris) 2006; 162(1): 71-81.

[4] Deeks SG. Immune dysfunction, inflammation, and accelerated aging in patients on antiretroviral therapy. Top HIV Med 2009; 17(4): 118-23.

[5] Brown TT, Glesby MJ. Management of the metabolic effects of HIV and HIV drugs. Nat Rev Endocrinol 2011; 8(1): 11-21.

[6] Hall DT, Ma JF, Marco SD, Gallouzi IE. Inducible nitric oxide synthase (iNOS) in muscle wasting syndrome, sarcopenia, and cachexia. Aging (Albany NY) 2011; 3(8): 702-15.

[7] Erlandson KM, Allshouse AA, Jankowski CM, et al. Functional impairment is associated with low bone and muscle mass among persons aging with HIV infection. J Acquir Immune Defic Syndr 2013; 63(2): 209-15.

[8] Wasserman P, Segal-Maurer S, Rubin DS. High prevalence of low skeletal muscle mass associated with male gender in midlife and older HIV-infected persons despite CD4 cell reconstitution and viral suppression. J Int Assoc Provid AIDS Care 2014; 13(2): 14552.

[9] Pillard F, Laoudj-Chenivesse D, Carnac G, et al. Physical activity and sarcopenia. Clin Geriatr Med 2011; 27(3): 449-70.

[10] O'Brien K, Nixon S, Tynan AM, Glazier RH. Effectiveness of aerobic exercise in adults living with HIV/AIDS: systematic review. Med Sci Sports Exerc 2004; 36(10): 1659-66.

[11] Farinatti PT, Borges JP, Gomes RD, Lima D, Fleck SJ. Effects of a supervised exercise program on the physical fitness and immunological function of HIV-infected patients. J Sports Med Phys Fitness 2010; 50(4): 511-8.

[12] Ciccolo JT, Jowers EM, Bartholomew JB. The benefits of exercise training for quality of life in HIV/AIDS in the post-HAART era. Sports Med 2004; 34(8): 487-99.
[13] Souza PM, Jacob-Filho W, Santarem JM, Zomignan AA, Burattini MN. Effect of progressive resistance exercise on strength evolution of elderly patients living with HIV compared to healthy controls. Clinics (Sao Paulo) 2011; 66(2): 261-6.

[14] Walrand S, Guillet C, Salles J, Cano N, Boirie Y. Physiopathological mechanism of sarcopenia. Clin Geriatr Med 2011; 27(3): 365-85.

[15] Cruz-Jentoft AJ, Baeyens JP, Bauer JM, et al. Sarcopenia: European consensus on definition and diagnosis: Report of the European Working Group on Sarcopenia in Older People. Age Ageing 2010; 39(4): 412-23.

[16] Taivassalo T, Haller RG. Exercise and training in mitochondrial myopathies. Med Sci Sports Exerc 2005; 37(12): 2094-101.

[17] Jones TE, Stephenson KW, King JG, et al. Sarcopeniamechanisms and treatments. J Geriatr Phys Ther 2009; 32(2): 83-9.

[18] O'Brien K, Tynan AM, Nixon S, Glazier RH. Effects of progressive resistive exercise in adults living with HIV/AIDS: systematic review and meta-analysis of randomized trials. AIDS Care 2008; 20(6): 631-53.

[19] Hunter GR, McCarthy JP, Bamman MM. Effects of resistance training on older adults. Sports Med 2004; 34(5): 329-48.

[20] Clingerman EM. Participation in physical activity by persons living with HIV disease. J Assoc Nurses AIDS Care 2003; 14(5): 59-70.

[21] Spence DW, Galantino ML, Mossberg KA, Zimmerman SO. Progressive resistance exercise: effect on muscle function and anthropometry of a select AIDS population. Arch Phys Med Rehabil 1990; 71(9): 644-8.

[22] Dudgeon WD, Phillips KD, Carson JA, et al. Counteracting muscle wasting in HIV-infected individuals. HIV Med 2006; 7(5): 299310 .

[23] Souza PM, Jacob-Filho W, Santarem JM, et al. Progressive resistance training in elderly HIV-positive patients: does it work? Clinics (Sao Paulo) 2008; 63(5): 619-24.

[24] Lindegaard B, Hansen T, Hvid T, et al. The effect of strength and endurance training on insulin sensitivity and fat distribution in human immunodeficiency virus-infected patients with lipodystrophy. J Clin Endocrinol Metab 2008; 93(10): 3860-9.

[25] Aagaard P, Simonsen EB, Andersen JL, Magnusson P, DyhrePoulsen P. Neural adaptation to resistance training: changes in evoked V-wave and H-reflex responses. J Appl Physiol 2002; 92(6): 2309-18.

[26] Baumgartner RN, Koehler KM, Gallagher D, et al. Epidemiology of sarcopenia among the elderly in New Mexico. Am J Epidemiol 1998; 147(8): 755-63.

[27] Janssen I, Baumgartner RN, Ross R, Rosenberg IH, Roubenoff R. Skeletal muscle cutpoints associated with elevated physical disability risk in older men and women. Am J Epidemiol 2004; 159(4): 413-21.

[28] Kelly TL, Berger N, Richardson TL. DXA body composition: theory and practice. Appl Radiat Isot 1998; 49(5-6): 511-3.

[29] Pincivero DM, Lephart SM, Karunakara RA. Reliability and precision of isokinetic strength and muscular endurance for the quadriceps and hamstrings. Int J Sports Med 1997; 18(2): 113-7.

[30] Gallagher D, Visser M, De Meersman RE, et al. Appendicular skeletal muscle mass: effects of age, gender, and ethnicity. J Appl Physiol (1985) 1997; 83(1): 229-39.

[31] Kruger K, Mooren FC. Exercise-induced leukocyte apoptosis. Exerc Immunol Rev 2014; 20: 117-34.

[32] Garber CE, Blissmer B, Deschenes MR, et al. American College of Sports Medicine position stand. Quantity and quality of exercise for developing and maintaining cardiorespiratory, musculoskeletal, and neuromotor fitness in apparently healthy adults: guidance for prescribing exercise. Med Sci Sports Exerc 2011; 43(7): 1334-59.

[33] Sakkas GK, Mulligan K, Dasilva M, et al. Creatine fails to augment the benefits from resistance training in patients with HIV infection: a randomized, double-blind, placebo-controlled study. PLoS One 2009; 4(2): e4605.

[34] Roubenoff R, Wilson IB. Effect of resistance training on selfreported physical functioning in HIV infection. Med Sci Sports Exerc 2001; 33(11): 1811-7.

[35] Shevitz AH, Wilson IB, McDermott AY, et al. A comparison of the clinical and cost-effectiveness of 3 intervention strategies for AIDS wasting. J Acquir Immune Defic Syndr 2005; 38(4): 399-406.

[36] Agin D, Gallagher D, Wang J, et al. Effects of whey protein and resistance exercise on body cell mass, muscle strength, and quality of life in women with HIV. AIDS 2001; 15(18): 2431-40. 
[37] Bhasin S, Storer TW, Javanbakht M, et al. Testosterone replacement and resistance exercise in HIV-infected men with weight loss and low testosterone levels. JAMA 2000; 283(6): 76370 .

[38] Strawford A, Barbieri T, Van Loan M, et al. Resistance exercise and supraphysiologic androgen therapy in eugonadal men with HIV-related weight loss: a randomized controlled trial. JAMA 1999; 281(14): 1282-90.

[39] Sattler FR, Jaque SV, Schroeder ET, et al. Effects of pharmacological doses of nandrolone decanoate and progressive resistance training in immunodeficient patients infected with human immunodeficiency virus. J Clin Endocrinol Metab 1999; 84(4): 1268-76.

[40] Lox CL, McAuley E, Tucker RS. Aerobic and resistance exercise training effects on body composition, muscular strength, and cardiovascular fitness in an HIV-1 population. Int J Behav Med 1996; 3(1): 55-69.

[41] Yarasheski KE, Scherzer R, Kotler DP, et al. Age-related skeletal muscle decline is similar in HIV-infected and uninfected individuals. J Gerontol A Biol Sci Med Sci 2011; 66(3): 332-40.

[42] Perez-Moreno F, Camara-Sanchez M, Tremblay JF, et al. Benefits of exercise training in Spanish prison inmates. Int $\mathrm{J}$ Sports Med 2007; 28(12): 1046-52.

[43] Dolan SE, Frontera W, Librizzi J, et al. Effects of a supervised home-based aerobic and progressive resistance training regimen in women infected with human immunodeficiency virus: a randomized trial. Arch Intern Med 2006; 166(11): 1225-31.

[44] Driscoll SD, Meininger GE, Lareau MT, et al. Effects of exercise training and metformin on body composition and cardiovascular indices in HIV-infected patients. AIDS 2004; 18(3): 465-73.

[45] Driscoll SD, Meininger GE, Ljungquist K, et al. Differential effects of metformin and exercise on muscle adiposity and metabolic indices in human immunodeficiency virus-infected patients. J Clin Endocrinol Metab 2004; 89(5): 2171-8.

[46] Grinspoon S, Corcoran C, Parlman K, et al. Effects of testosterone and progressive resistance training in eugonadal men with AIDS wasting. A randomized, controlled trial. Ann Intern Med 2000; 133(5): 348-55.

[47] Mutimura E, Stewart A, Crowther NJ, Yarasheski KE, Cade WT. The effects of exercise training on quality of life in HAART-treated HIV-positive Rwandan subjects with body fat redistribution. Qual Life Res 2008; 17(3): 377-85.

[48] Hand GA, Phillips KD, Dudgeon WD, et al. Moderate intensity exercise training reverses functional aerobic impairment in HIVinfected individuals. AIDS Care 2008; 20(9): 1066-74.

[49] Rigsby LW, Dishman RK, Jackson AW, Maclean GS, Raven PB. Effects of exercise training on men seropositive for the human immunodeficiency virus-1. Med Sci Sports Exerc 1992; 24(1): 612.

[50] Terry L, Sprinz E, Stein R, et al. Exercise training in HIV-1infected individuals with dyslipidemia and lipodystrophy. Med Sci Sports Exerc 2006; 38(3): 411-7.

[51] Neidig JL, Smith BA, Brashers DE. Aerobic exercise training for depressive symptom management in adults living with HIV infection. J Assoc Nurses AIDS Care 2003; 14(2): 30-40.
[52] Baigis J, Korniewicz DM, Chase G, et al. Effectiveness of a homebased exercise intervention for HIV-infected adults: a randomized trial. J Assoc Nurses AIDS Care 2002; 13(2): 33-45.

[53] Smith BA, Neidig JL, Nickel JT, et al. Aerobic exercise: effects on parameters related to fatigue, dyspnea, weight and body composition in HIV-infected adults. AIDS 2001; 15(6): 693-701.

[54] Perna FM, LaPerriere A, Klimas N, et al. Cardiopulmonary and CD4 cell changes in response to exercise training in early symptomatic HIV infection. Med Sci Sports Exerc 1999; 31(7): 973-9.

[55] Terry L, Sprinz E, Ribeiro JP. Moderate and high intensity exercise training in HIV-1 seropositive individuals: a randomized trial. Int J Sports Med 1999; 20(2): 142-6.

[56] Stringer WW, Berezovskaya M, O'Brien WA, Beck CK, Casaburi $\mathrm{R}$. The effect of exercise training on aerobic fitness, immune indices, and quality of life in HIV+ patients. Med Sci Sports Exerc 1998; 30(1): 11-6.

[57] LaPerriere AR, Antoni $\mathrm{MH}$, Schneiderman N, et al. Exercise intervention attenuates emotional distress and natural killer cell decrements following notification of positive serologic status for HIV-1. Biofeedback Self Regul 1990; 15(3): 229-42.

[58] Yarasheski KE, Tebas P, Stanerson B, et al. Resistance exercise training reduces hypertriglyceridemia in HIV-infected men treated with antiviral therapy. J Appl Physiol (1985) 2001; 90(1): 133-8.

[59] Davies GI, Heiderscheit B, Brinks K. In Brown LE, Ed. Isokinetics in human performance, Champaign, Human Kinetics 2000; pp. 324.

[60] Chapplain JM, Beillot J, Begue JM, et al. Mitochondrial abnormalities in HIV-infected lipoatrophic patients treated with antiretroviral agents. J Acquir Immune Defic Syndr 2004; 37(4): 1477-88.

[61] Janssen I, Shepard DS, Katzmarzyk PT, Roubenoff R. The healthcare costs of sarcopenia in the United States. J Am Geriatr Soc 2004; 52(1): 80-5.

[62] Buehring B, Kirchner E, Sun Z, Calabrese L. The frequency of low muscle mass and its overlap with low bone mineral density and lipodystrophy in individuals with HIV--a pilot study using DXA total body composition analysis. J Clin Densitom 2012; 15(2): 22432.

[63] Pyka G, Lindenberger E, Charette S, Marcus R. Muscle strength and fiber adaptations to a year-long resistance training program in elderly men and women. J Gerontol 1994; 49(1): M22-7.

[64] Gomes-Neto M, Conceicao CS, Oliveira Carvalho V, Brites C. A systematic review of the effects of different types of therapeutic exercise on physiologic and functional measurements in patients with HIV/AIDS. Clinics (Sao Paulo) 2013; 68(8): 1157-67.

[65] Shephard RJ. Physical impairment in HIV infections and AIDS: responses to resistance and aerobic training. J Sports Med Phys Fitness 2015 [Epub ahead of print].

[66] Gomes Neto M, Ogalha C, Andrade AM, Brites C. A systematic review of effects of concurrent strength and endurance training on the health-related quality of life and cardiopulmonary status in patients with HIV/AIDS. Biomed Res Int 2013; 2013: 319524.

This is an open access article licensed under the terms of the Creative Commons Attribution Non-Commercial License (http://creativecommons.org/licenses/by-nc/ $3.0 /$ ) which permits unrestricted, non-commercial use, distribution and reproduction in any medium, provided the work is properly cited. 